\title{
Irradiation effect on impact fracture behavior of A508-3 steel in ductile-to-brittle transition range
}

\author{
Ziyang Zhou ${ }^{\mathrm{a}}$, Zhenfeng Tong ${ }^{\mathrm{a}, *}$, Guian Qian ${ }^{\mathrm{b}, *}$, Weihua Zhong ${ }^{\mathrm{a}}$, Chenglong Wang ${ }^{\mathrm{a}}$, \\ Wen Yang ${ }^{\mathrm{a}}$, Filippo Berto ${ }^{\mathrm{C}}$ \\ ${ }^{\text {a }}$ China Institute of Atomic Energy, Beijing, China \\ ${ }^{\mathrm{b}}$ State Key Laboratory for Nonlinear Mechanics (LNM), Institute of Mechanics, Chinese Academy of Sciences, Beijing, China \\ ${ }^{\mathrm{c}}$ Department of Mechanical and Industrial Engineering, Norwegian University of Science and Technology (NTNU), Richard Birkelands vei 2b, 7491 \\ Trondheim, Norway
}

\section{A R T I C L E I N F O}

\section{Keywords:}

Reactor pressure vessel

Neutron embrittlement

Crack propagation

Plastic deformation

Charpy impact test

Scanning electron microscopy

\begin{abstract}
A B S T R A C T
The mechanical performance of reactor pressure vessel (RPV) materials is an important factor in determining the safety and economics of the operation of a nuclear power plant. The ductile-tobrittle transition temperature (DBTT) tested by Charpy impact test is an important parameter for evaluating the RPV embrittlement. In this paper, the Charpy impact test of RPV steel prior and after irradiation was carried out at different temperatures. The fracture morphology was observed by scanning electron microscopy. The irradiation effect on the impact fracture behavior was analyzed in the DBTT temperature zone. Results show that in the DBTT range, the crack initiation and propagation energy are obviously reduced for the irradiated material. After irradiation, the dimple area on the fracture surface is significantly reduced, and the distance from the crack initiation source to the gap is decreased. For the RPV steel with low Cu steel content, matrix damage becomes the main factor on material irradiation embrittlement.
\end{abstract}

\section{Introduction}

Reactor pressure vessel (RPV) has been irreplaceable due to its large size and has been the third barrier to prevent radioactive material from overflowing. Since the RPV material is ferritic steel, which is body-centered cubic crystal structure, the material demonstrates DBTT characteristics and the material will be brittle when temperature is below DBTT. Moreover, RPV materials are sensitive to neutron irradiation. Long-term neutron irradiation will cause neutron embrittlement. This will lead to an increase in the DBTT and may induce brittle fracture, and even cause a nuclear accident. Therefore, neutron irradiation embrittlement is a big threat of RPV material failure, which is crucial for the structural integrity of RPV [1-3]. In the long term operation of structures, the integrity should be analyzed using different methods, e.g. deterministic and probabilistic methods [4-6]. The different ageing mechanism and failure modes should also be studied and advanced crack detection setups are developed [7-9]. In this paper, the neutron irradiation is considered as the ageing mechanism.

In the structural integrity analysis of RPV containing cracks, a lot of effects should be considered from material aspects, as well as from crack driving force aspect. From material part, the mechanical behavior of the irradiated materials should be tested using different methods in the nuclear safety assessment. In order to evaluate the performance of the irradiated material, Charpy impact test is normally used to characterize the DBTT properties of RPV due to the simple application of the testing method. As the RPV

\footnotetext{
* Corresponding authors.

E-mail addresses: tony_tzf@163.com (Z. Tong), qianguian@imech.ac.cn (G. Qian).
} 
material changes from ductile to brittle, its material performance may decrease significantly accordingly. The impact fracture mechanism may change from ductile fracture to brittle fracture after irradiation and the microscopic fracture mechanism of the material may also change. As the Charpy impact test is easy to perform, the application of the results to the real structure is still questionable. Charpy impact test induces a high strain rate, which is different from the engineering structures. The other method to characterize the mechanical behavior is the tensile test and fracture mechanics test using small specimens, e.g. compact tension specimens. This is a more realistic and precise method, as the strain rate in this experiment is quasi static, which is similar to the engineering structures. Thus, it is important to correlate the fracture parameters from Charpy impact test with those from quasi static test. There are a lot of studies to link the fracture toughness $\mathrm{K}_{\mathrm{Ic}}$ using different methods $[10,11]$. Moreover, in the DBTT range, the impact properties of RPV materials are very sensitive to temperature changes. Small temperature changes can also cause great changes in impact properties. It is important to use DBTT change obtained by the impact test to characterize the neutron irradiation embrittlement of RPV. This is also the common engineering practice in nuclear industry. From the crack driving force aspect, a critical topic is transferring the fracture parameters obtained from these small specimens to big engineering structures. In order to solve this topic, it is important to consider crack tip constraint effect and the so-called 3D effects [12-14]. The in-plane and out-of-plane constraint effects are commonly studied in order to precisely characterize the crack tip field. It is thus important to find a relation between the fracture parameters from different specimen sizes. Both elastic and elastic-plastic fracture mechanics should be applied based on energy criterion. As the nature of fracture consists the energy dissipation, the energy based criterion, e.g. strain energy density criterion and local energy density criterion are developed to study the fracture behavior of the materials containing cracks [15-17]. However, in the present study, it is more focused on the fracture characterization of the irradiated material.

Therefore, this paper aims to study the Charpy impact performance of the irradiated RPV steel A508-3 and the corresponding fracture mechanisms. The Chinese domestic irradiated material is tested and characterized using fracture mechanics method.

\section{Material, specimen and experimental procedure}

\subsection{Material and specimen}

The material used in this paper is the domestic pressure vessel steel A508-3 steel. The specific composition is shown in Table 1. The experimental samples were divided into two groups: unirradiated and irradiated samples. The sample geometry is shown in Fig. 1. The sample preparation procedure is referred to the national standard method. The samples are taken from the $1 / 4 \mathrm{~T}$ ( $\mathrm{T}$ is the thickness) of the forging piece, and the axial direction of the sample is perpendicular to the main machining direction of the forging (i.e., radial direction). The irradiated samples simulate the 60-year state of the AP1000 reactor. The samples were kept in the 49-2 reactor for 145 days of irradiation test, where the neutron flux was $8-10 \times 10^{12} \mathrm{n} / \mathrm{cm}^{2} \cdot \mathrm{s}$ and the neutron irradiation dose reached about $10 \times 10^{19} \mathrm{n} / \mathrm{cm}^{2}$.

The impact test was carried out by the OLSEN impact tester in accordance with GB/T 229 regulation (Metal Charpy Notched Impact Test Method). The working modes of the temperature control furnace are resistance wire heating and liquid nitrogen spraying. The accuracy control meets the standard $\pm 2{ }^{\circ} \mathrm{C}$, and the test compensation temperature is set according to the standard, see Table 2 . The impact test temperature was determined by the test process, which gives the following 7 temperatures: $70,20,-5,-20,-30$, -40 and $-60^{\circ} \mathrm{C}$. Each temperature consists of 3 effective impact data.

\subsection{Charpy impact test procedure}

It is a conventional procedure to use impact energy to characterize material toughness. Energy $\mathrm{E}_{\mathrm{t}}(\mathrm{J})$ is evaluated according to the curve of Load versus time. In the Charpy impact test, the load, displacement are recorded at different time. They will be used to

Table 1

Chemical composition of A508-3 steel.

\begin{tabular}{lll}
\hline Element & Experiment material & National standard \\
\hline $\mathrm{C}$ & 0.18 & $0.16-0.22$ \\
$\mathrm{Si}$ & 0.16 & $0.10-0.30$ \\
$\mathrm{Mn}$ & 1.41 & $1.20-1.60$ \\
$\mathrm{P}$ & $<0.005$ & $<0.008$ \\
$\mathrm{~S}$ & 0.0027 & $<0.008$ \\
$\mathrm{Cr}$ & 0.12 & $\leq 0.2$ \\
$\mathrm{Ni}$ & 0.75 & $0.50-0.80$ \\
$\mathrm{Mo}$ & 0.46 & $0.43-0.57$ \\
$\mathrm{Cu}$ & $<0.02$ & $\leq 0.08$ \\
$\mathrm{~V}$ & 0.005 & $\leq 0.01$ \\
$\mathrm{Al}$ & 0.02 & $\leq 0.04$ \\
$\mathrm{Co}$ & $<0.02$ & $\leq 0.03$ \\
$\mathrm{As}$ & 0.003 & $\leq 0.010$ \\
$\mathrm{Sn}$ & 0.002 & $\leq 0.010$ \\
$\mathrm{Sb}$ & 0.0015 & $\leq 0.005$ \\
$\mathrm{~B}$ & 0.0002 & $\leq 0.0005$ \\
\hline
\end{tabular}




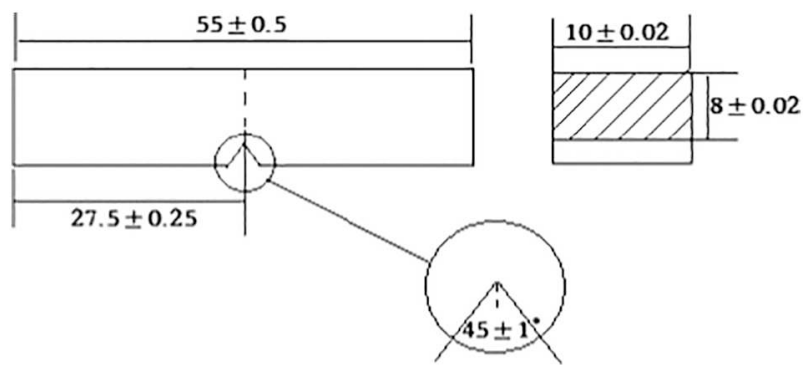

Fig. 1. Impact specimen size.

Table 2

Test compensation temperature.

\begin{tabular}{ll}
\hline Test temperature,${ }^{\circ} \mathrm{C}$ & Compensation temperature, ${ }^{\circ} \mathrm{C}$ \\
\hline $30-200$ & $1-5$ \\
0 to -60 & -1 to -2 \\
-60 to -100 & -2 to -3 \\
\hline
\end{tabular}

calculate the energy consumed at different time. For brittle material, the energy can be small to fracture the specimen. For ductile material, the energy will be larger. The impact energy $E_{t}$ consists of the crack formation energy $E_{i}$ and the crack growth energy $E_{p}$. Therefore, in order to analyze the influence of irradiation on $E_{i}$ and $E_{p}$, the Charpy impact test curves after irradiation will be studied in the following.

Fig. 2 is a typical impact load-displacement curve. The right side of the picture is the energy axis, and the blue curve corresponds to the area enclosed by the load and displacement, which is the instantaneous total impact energy value. According to the impact process, the curve is divided into different sections. It can be seen that the impact fracture process consists of elastic deformation (OA), plastic deformation (AB), crack stability expansion (BC), crack instability expansion (CD) and tearing process (after D) [18].

The OA segment is an elastic deformation part, and the tensile stress is formed at the notch after being loaded. The area enclosed by the curve is the elastic deformation energy $\mathrm{E}_{\mathrm{e}}$ which corresponding to the point a of the energy curve. It can be seen that the elastic deformation energy of the material is very small. The AB segment is a plastic deformation part. At this stage, a large amount of plastic deformation occurs and that deformation strengthening is generated. The area enclosed by the curve is plastic deformation energy $E_{\mathrm{d}}$. As the load increases, the plastic deformation runs through the entire notch section. The root of the notch begins to shrink. Accordingly, the bearing area decreases and the load bearing capacity decreases as the specimen reaches the maximum load. At the point B, the micropores grow and gradually connect, forming a microcrack. So the OB segment is the crack initiation part, which corresponds to the crack formation energy $\mathrm{E}_{\mathrm{i}}$. The $\mathrm{BC}$ segment is a stable extension part of the crack, where the speed is slow and the curve shows a steep downward trend. After the microcrack is formed, the plastic deformation occurs due to stress concentration, which causes crack further grow. The area enclosed by the curve is the crack stable propagation energy Ep ${ }_{1}$, corresponding to the fibrous area of fracture. The CD segment is the crack-stabilized extension. When the load reaches the C-point, the ductile fracture becomes brittle fracture, and the load suddenly drops, corresponding to the white-light crystalline fracture morphology of the radiation zone in the fracture photograph. The area enclosed by the curve is the crack instability propagation energy $\mathrm{E}_{\mathrm{p} 2}$, and it can be seen that the part of the energy is very small. After the D point is the tearing part, the load is slowly reduced until it is zero, and the area enclosed by the curve is the tearing energy $\mathrm{E}_{\mathrm{p} 3}$, which corresponds to the shear lip fraction in the macro fracture photograph.

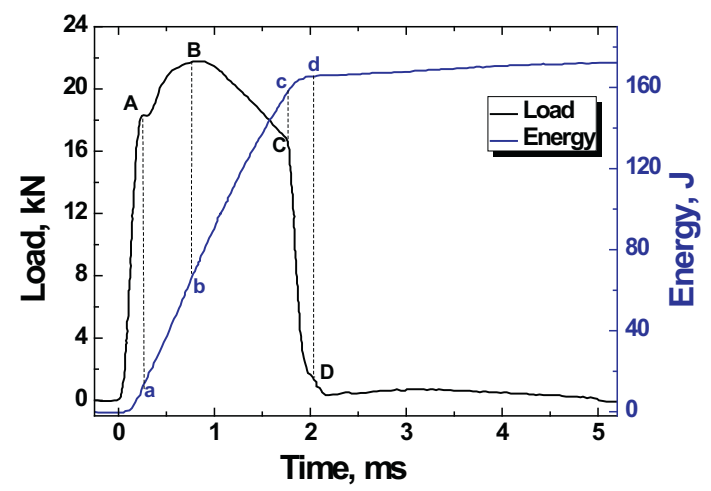

Fig. 2. Load-displacement curve for a typical impact test. 


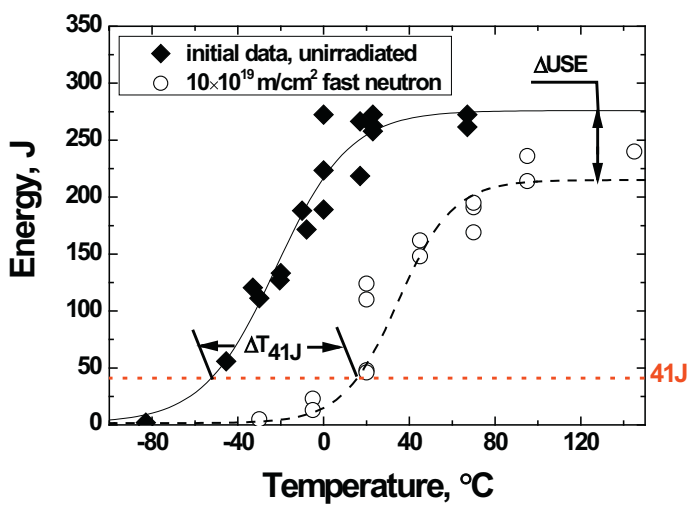

Fig. 3. Impact energy - temperature curve.

\section{Results}

\subsection{Charpy impact test results}

\subsubsection{Ductile-to-Brittle transition temperature}

Fig. 3 shows the Charpy impact data before and after irradiation and the impact energy versus temperature curve is fitted by the hyperbolic tangent function. As can be seen, the impact energy gradually decreases as the temperature decreases. The shape of the impact curve is similar before and after irradiation, but the whole curve moves to the lower right part after irradiation. The exact data is shown in Table 3. The data in Table 3 is related with Fig. $3 . \mathrm{T}_{41 \mathrm{~J}}$ is obtained from horizontal line intersected with the energy versus temperature curve. It is assumed that $\Delta \mathrm{RT}_{\mathrm{NDT}}$ is equal to $\Delta \mathrm{T}_{41 \mathrm{~J}}$ for the irradiated specimen. For the upper shelf energy, the energy and the shift between unirradiated and irradiated specimen are clearly shown in Fig. 3. It is quantified that the USE (upper shelf energy) after irradiation decreases by $61 \mathrm{~J}$, and the DBTT increases by $68^{\circ} \mathrm{C}$, i.e. $\triangle \mathrm{T}_{41 \mathrm{~J}}=68^{\circ} \mathrm{C}, \triangle \mathrm{USE}=61 \mathrm{~J}$. These results show that DBTT increases and the upper shelf energy decreases after irradiation, which is the influence of neutron embrittlement. As shown in Fig. 3 , detailed analysis was carried out selecting four representative temperatures in the DBTT range at $-30^{\circ} \mathrm{C},-5{ }^{\circ} \mathrm{C}, 20^{\circ} \mathrm{C}$ and $70{ }^{\circ} \mathrm{C}$.

\subsubsection{Charpy impact test of specimens before and after irradiation}

Comparing the crack initiation energy $E_{i}$ and the propagation energy $E_{p}$ (see Fig. 4), it is seen that $E_{i}$ and $E_{p}$ of the irradiated material are greatly reduced and the impact properties of the specimen are lowered in the DBTT regime. This is due to the embrittlement of the material caused by the irradiation.

Firstly, the crack initiation energy for the unirradiated specimens show that $E_{i}$ increases first and then decreases in the DBTT range. As the temperature increases, the material gradually becomes tough, and the proportion of ductile fracture increases. The crack initiation energy becomes larger during this process. At $70{ }^{\circ} \mathrm{C}$, although the specimens are still quite ductile, the material strength becomes low, resulting in the reduction of the crack initiation energy. The crack initiation energy increases after irradiation. This is because the material transforms into ductile with temperature, which is also reflected in the macro fracture, as shown in Fig. 5. Secondly, the crack extension energy is analyzed. With the temperature increasing, the material becomes tougher and the crack growth energy prior irradiation increases in the DBTT range. However, the crack growth energy after irradiation also increases with temperature. Finally, the fracture energy before and after irradiation was analyzed. At $-30^{\circ} \mathrm{C}$, the crack initiation energy after irradiation was reduced. With the increase of temperature, the downward trend gradually became flat. The crack initiation energy after irradiation at $70{ }^{\circ} \mathrm{C}$ is slightly decreased. $E_{i}$ is decreased due to neutron embrittlement. Neutron embrittlement leads to the formation of micro cracks by point defect, dislocations, and segregation of atoms in the grain boundary. This is an open question and has been studied over decades. The present study aims to quantify the neutron embrittlement effect using the Charpy impact test. The crack propagation energy $E_{p}$ is greatly reduced at the four temperatures in the DBTT range, which shows the main decreased portion of the USE (upper shelf energy) after irradiation is the crack propagation energy. This proves that the material toughness mainly depends on the crack propagation energy $E_{p}$. The smaller the $E_{p}$ is, the lower the impact toughness is. The impact toughness of the material is significantly reduced by irradiation.

Table 3

Experimental data before and after irradiation.

\begin{tabular}{llll}
\hline & Unirradiated & Irradiated & $\triangle$ \\
\hline T41 J & $-52{ }^{\circ} \mathrm{C}$ & $16^{\circ} \mathrm{C}$ & $68^{\circ} \mathrm{C}$ \\
Upper shelf energy & $276 \mathrm{~J}$ & $215 \mathrm{~J}$ & $61 \mathrm{~J}$ \\
\hline
\end{tabular}




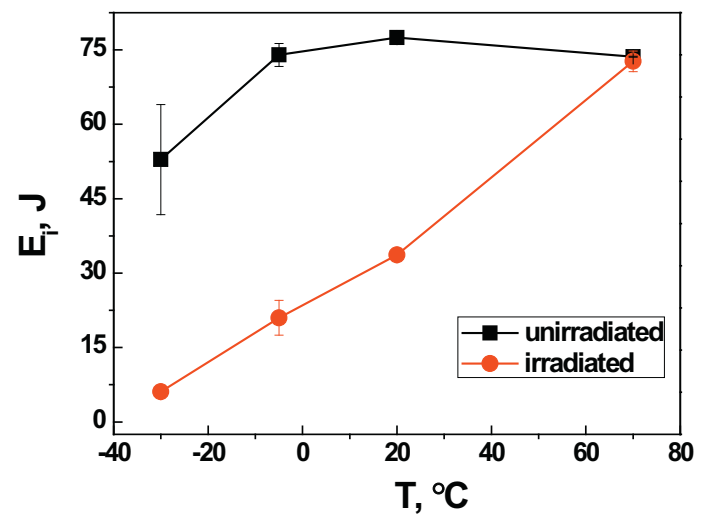

(a)

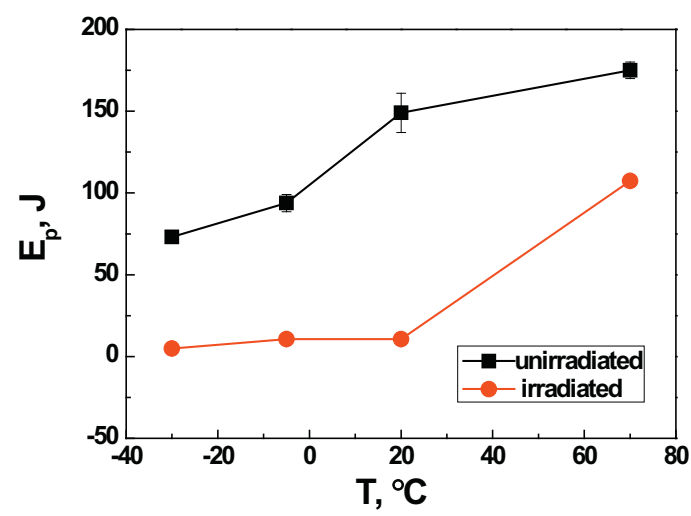

(b)

Fig. 4. (a) comparison of $E_{i}$ (crack initiation energy) before and after irradiation (b) Comparison of $E_{p}$ (crack propagation energy) before and after irradiation.

$-30{ }^{\circ} \mathrm{C}$
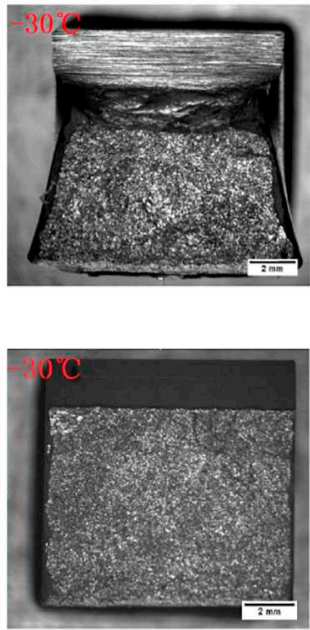

$-5{ }^{\circ} \mathrm{C}$
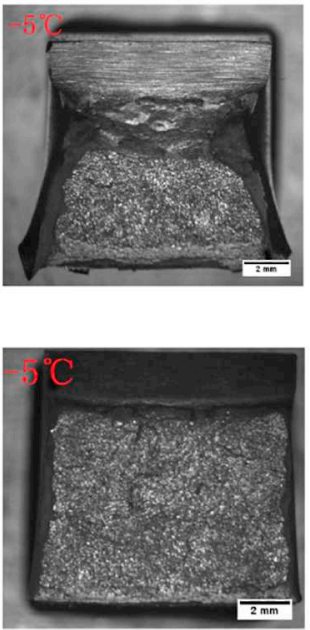

$20{ }^{\circ} \mathrm{C}$
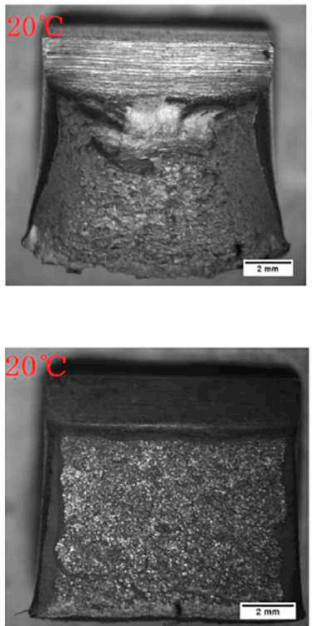

$70{ }^{\circ} \mathrm{C}$
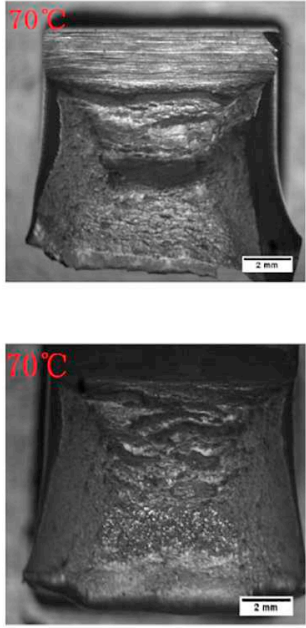

Fig. 5. Macroscopic fracture surfaces for the impact specimens tested at different temperatures before and after irradiation.

\subsection{Microscopic fracture surface and mechanism analysis}

\subsubsection{Microscopic analysis of Charpy impact specimens}

The morphology of the Charpy impact specimen consists of three parts: fiber zone, radiation zone and shear lip. The proportion of these three zones can reflect the impact toughness of the material. The larger shear lip and fiber area indicate better material toughness. In this paper, four different temperature in the DBTT range were selected for comparative study, which were $-30{ }^{\circ} \mathrm{C}$, $-5^{\circ} \mathrm{C}, 20^{\circ} \mathrm{C}$ and $70^{\circ} \mathrm{C}$.

Fig. 5 shows the fracture morphology of the samples before and after irradiation. The impact test was carried out at $-30{ }^{\circ} \mathrm{C}$. It is seen that the fracture surface before the irradiation is uneven and the plastic deformation is obvious. The area of the shear lip and the fiber area is large, meaning the percentage (36\%) of ductile fracture area is quite large. In contrast, the fracture surface of the specimens after irradiation is quite flat and the shear lip and fiber area are obviously reduced. The percentage of brittle fracture area is obviously increased and the ductile fracture area is only 6\%. The above phenomena show that for the irradiated A508-3 steel, the ductile fracture area is reduced and thus neutron embrittlement occurs.

The scanning electron micrograph of the impact specimen before and after irradiation at $-30{ }^{\circ} \mathrm{C}$ is further studied and is shown in Fig. 6. The area of the dimple portion of the fracture of the unirradiated sample was large, and significant plastic deformation occurred. After irradiation, the dimple area on the specimen fracture surface is very small, which means that the irradiation causes the material to be embrittled. Comparing the scanning electron micrographs of the impact fractures before and after irradiation at different temperatures, the area of the fractured dimples after irradiation is significantly reduced. The difference is maximum at room temperature, which can cause embrittlement of the materials. As the temperature increases, the dimple portion of the impact fracture 


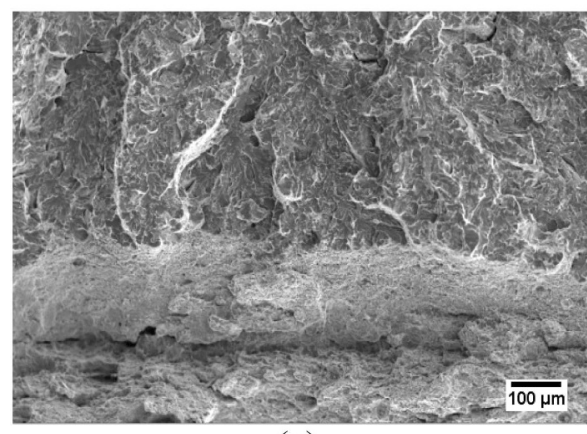

(a)

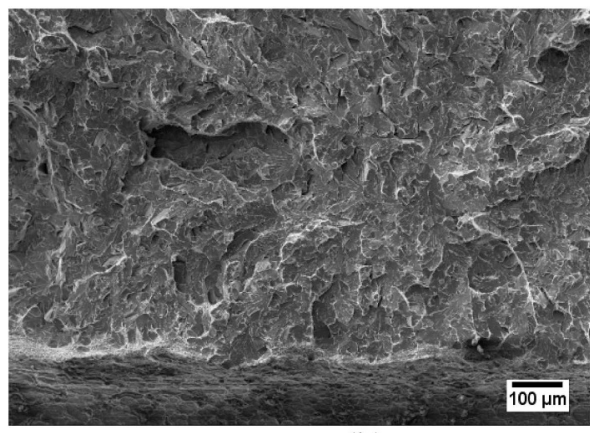

(b)

Fig. 6. (a) Scanning electron microscopy of unirradiated impact sample (b) impact sample after irradiation at $-30^{\circ} \mathrm{C}$.

of the sample before and after irradiation increases. The results obtained from the analysis are consistent with the results calculated from the curve (Fig. 2). It is noticed that the impact test is tested at $-30{ }^{\circ} \mathrm{C}$ and were overserved in SEM. More tests for the irradiated specimens are still in progress. It is interesting to compare the results in the future. The experiment takes a long time and needs a hot lab to perform such test for irradiated specimens. This is a challenging task.

It is known that irradiation leads to embrittlement of RPV steel by the following three main factors: nano-scale Cu-rich solute precipitation, matrix damage, brittle elements such as $\mathrm{P}$ segregation at grain boundaries [19,20]. Solute precipitation includes two forms of existence: Cu-rich precipitation and $\mathrm{Mn}$-rich, Ni precipitation. Cu-precipitate is dominant in irradiation embrittlement in pressure vessel steels containing $0.1 \%$ or more of $\mathrm{Cu}$ [21]. However, due to the strict control of the Cu content of the test material, its content is lower than $<0.02$, which belongs to low copper steel. So solute precipitation is not the main factor of irradiation embrittlement. Therefore, the segregation of P element in grain boundary leads to embrittlement. It is studied that for low Cu steel RPV and under low neutron irradiation condition, matrix damage, such as dislocation loops, microvoids, and point defects-solute atom complexes [22,23], are the main factors in irradiation embrittlement hardening.

\subsubsection{Effect of irradiation on Charpy impact toughness by Griffith theory}

The cleavage fracture of low-alloy steel is generally controlled by micro-crack propagation. The fracture process includes: plastic deformation, micro-crack formation, crack propagation, micro-crack reaching the critical dimension, unstable expansion and finally the sample fracture [24]. After analyzing the fracture phenomenon of the metal member, Orowan corrected the Griffith condition and obtained the following critical stress.

$$
\begin{aligned}
& \sigma_{c}=\left(\frac{2 E \gamma_{p}}{\pi a}\right)^{1 / 2} \quad \text { for plane stress } \\
& \sigma_{c}=\left(\frac{2 E \gamma_{p}}{\pi a\left(1-v^{2}\right)}\right)^{1 / 2} \quad \text { for plane strain }
\end{aligned}
$$

It is known that irradiation decreases the surface energy to create a surface crack, which makes the brittle fracture more easily. Griffith criterion is widely used criteria in fracture behavior of materials and is used in this study because the surface energy for crack initiation can be applied for the neutron embrittlement analysis. Neutron embrittlement leads to the formation of micro cracks by point defect, dislocations, and segregation of atoms in the grain boundary. The macro effect of neutron embrittlement is the decrease of surface energy for crack initiation in Griffith criterion. According to the Griffith formula, $\sigma_{\mathrm{c}}$ is in proportional to the critical crack size. Cleavage fracture criteria is shown:

$$
\sigma=Q \sigma_{s}>\sigma_{f}
$$

where $Q$ is stress strengthening coefficient, $\sigma_{s}$ is the yield stress and $\sigma_{\mathrm{f}}$ is the facture stress. From Eq. (3), it is seen that within the characteristic distance ahead of the crack, the cleavage fracture will occur when the normalized stress $\sigma$ is greater than the local fracture stress $\sigma_{\mathrm{f}}$. According to the Griffith formula, the larger the critical dimension a is, the smaller the $\sigma_{\mathrm{f}}$ is, and the more likely the cleavage fracture occurs. Conversely, when the critical crack size is small and $\sigma_{\mathrm{f}}$ is large, a large principal stress is required to cause the cleavage fracture. At this time, the crack continues grow, and the peak of the principal stress is continuously increased and away from the gap. The distance from the source to the root of the notch is also significantly increased. Therefore, from the cracking initiator to the notch root, the impact toughness of the specimen can be qualitatively estimated. It can be clearly seen from the impact fracture diagram that the distance from the crack initiation source to the sample fracture is significantly reduced after irradiation. The impact toughness of the specimen is lower than that of the specimen before irradiation.

It should be noted that 3D effect is a very important factor. It may play an important role in fracture behavior, especially in the constraint effect. This is our future work to correlate the fracture energy with the irradiated specimen considering 3D fracture behavior [12-14]. Griffith criterion is widely used criteria in fracture behavior of materials and is used in this study because the surface energy. Local energy density and strain energy density [15-17] can also be employed for the brittle fracture analysis, which 
may be our future topic. It is also important to employ the probabilistic concept [25-27] to further understand the statistical behavior of the material uncertainty shown in the experiment.

\section{Summary}

The Charpy impact test of the RPV material before and after irradiation was carried out. The fracture morphology at different temperatures was analyzed and the fracture mechanism was studied. The following conclusions are drawn:

1. The impact energy-temperature curve of the base material sample is moved to the lower right part after irradiation. The USE (upper shelf energy) decreases by $61 \mathrm{~J}$, and the DBTT increases by $68^{\circ} \mathrm{C}$, showing pronounced irradiation embrittlement.

2. The crack initiation energy and propagation energy of the Charpy impact specimen are significantly decreased after irradiation. The decrease of crack propagation energy after irradiation is the main reason for the severe reduction of impact toughness.

3. The impact fracture process of the specimen consists of three parts: fiber zone, radiation zone and shear lip. Irradiation leads to the reduction of dimple area and plastic deformation in the fracture surface.

4. It is verified from the Griffith formula that the distance from the crack initiator to the notch root is significantly reduced to characterize the mechanism of the impact toughness deterioration, and the impact toughness is significantly reduced.

\section{Acknowledgements}

Authors wish to acknowledge financial support from Large-scale Advanced PWR Nuclear Power Plant Major Projects (2018ZX06002008), and financial support by the National Natural Science Foundation of China (No.11872364).

\section{References}

[1] G. Qian, W.S. Lei, M. Niffengger, V.F. Gonzalez, On the temperature independence of statistical model parameters for cleavage fracture in ferritic steels, Philos. Mag. 98 (2018) 959-1004.2.

[2] G. Qian, W.S. Lei, L. Peng, Z. Yu, M. Niffengger, Statistical assessment of notch toughness against cleavage fracture of ferritic steels, Fatigue Fract. Eng. Mater. Struc. 41 (2018) 1120-1131.3.

[3] G. Qian, Y. Cao, M. Niffenegger, Y.J. Chao, W. Wu, Comparison of constraint analyses with global and local approaches under uniaxial and biaxial loadings, Eur. J. Mech. A Solids 69 (2018) 135-146.4.

[4] S.P. Zhu, S. Foletti, S. Beretta, Evaluation of size effect on strain-controlled fatigue behavior of a quench and tempered rotor steel: experimental and numerical study, Mater. Sci. Eng. A 735 (2018) 423-435.

[5] S.P. Zhu, Q. Liu, W. Peng, X.C. Zhang, Computational-experimental approaches for fatigue reliability assessment of turbine bladed disks, Int. J. Mech. Sci. 142-143 (2018) 502-517.

[6] D. Liao, S.P. Zhu, J.A.F.O. Correia, A.M.P. De Jesus, R. Calçada, Computational framework for multiaxial fatigue life prediction of compressor discs considering notch effects, Eng. Fract. Mech. (2018), https://doi.org/10.1016/j.engfracmech.2018.08.009 in press.

[7] D. Hu, T. Wang, Q. Ma, X. Liu, L. Shang, D. Li, J. Pan, R. Wang, Effect of inclusions on low cycle fatigue lifetime in a powder metallurgy nickel-based superalloy FGH96, Int. J. Fatigue 118 (2019) 237-248.

[8] J. Mao, D. Hu, F. Meng, X. Zhou, J. Song, R. Wang, Multiscale modeling of transgranular short crack growth during fatigue in polycrystalline metals, Int. J. Fatigue 116 (2018) 648-658.

[9] S.C. Wu, T.Q. Xiao, P.J. Withers, The imaging of failure in structural materials by synchrotron radiation X-ray micro-tomography, Eng. Fract. Mech. 182 (2017) $127-156$.

[10] M. Yu, Z. Luo, Y.J. Chao, Correlations between Charpy V-notch impact energy and fracture toughness of nuclear reactor pressure vessel (RPV) steels, Eng. Fract. Mech. 147 (2015) 187-202.

[11] H. Kim, J. Park, M. Kang, S. Lee, Interpretation of Charpy impact energy characteristics by microstructural evolution of dynamically compressed specimens in three tempered martensitic steels, Mater. Sci. Eng. A 649 (2016) 57-67.

[12] L.P. Pook, F. Berto, A. Campagnolo, State of the art of corner point singularities under in-plane and out-of-plane loading, Eng. Fract. Mech. 174 (2017) $391-403$.

[13] L.P. Pook, A. Campagnolo, F. Berto, P. Lazzarin, Coupled fracture mode of a cracked plate under anti-plane loading, Eng. Fract. Mech. 134 (2015) 2-9.

[14] L.P. Pook, A. Campagnolo, F. Berto, P. Lazzarin, Coupled fracture mode of a cracked disc under anti-plane loading, Eng. Fract. Mech. 128 (2014) 22-36.

[15] M.R. Moghaddam, M.R. Ayatollahi, F. Berto, The application of strain energy density criterion to fatigue crack growth behavior of cracked components, Theor. Appl. Fract. Mech. 97 (2018) 440-447.

[16] G. Meneghetti, A. Campagnolo, F. Berto, Averaged strain energy density estimated rapidly from the singular peak stresses by FEM: cracked bars under mixedmode (I+ III) loading, Eng. Fract. Mech. 167 (2016) 20-33.

[17] F. Berto, E. Barati, Fracture assessment of U-notches under three point bending by means of local energy density, Mater. Des. 32 (2011) 822-830.

[18] Chi Z D. Study on the Cause of Difference of Impact Energy Between Butt Weld Metal and Deposited Metal.

[19] M.K. Miller, K.F. Russell, J. Nucl. Mater. 371 (2007) 145.

[20] R.G. Cater, N. Soneda, K. Dohi, J.M. Hyde, C.A. English, W.L. Server, J. Nucl. Master 298 (3) (2001) 211.

[21] G.R. Odette, G.E. Lucas, Radiation Effect Defect Solids, 144 (1998), p. 189.

[22] T.J. Williams, D. Ellis, D.I. Swan, J. McGuire, S.P. Walley, C.A. English, J.H. Venables, P.H.N. de la cour Ray, Proc 2nd Int Symposium on Environmental Degradation of Materials in Nuclear Power Systems-water Reactors, ANS, Monterey, 1986, p. 323.

[23] E. Meslin, M. Lambrecht, M. Hernand ez-Mayoral, F. Bergner, L. Malerba, P. Pareige, B. Radiguet, A. Barbu, D. Gomez-Briceno, A. Ulbricht, A. Almazouzi, J. Nucl. Mater. 406 (2010) 73.

[24] Y. Tian, Metallographic Analysis of Fracture in Welding Zone, Vol. 112 (1990), p. 114.

[25] G. Qian, M. Niffenegger, M. Sharabi, N. Lafferty, Effect of non-uniform reactor cooling on fracture and constraint of a reactor pressure vessel, Fatigue Fract. Eng. Mater. Struct. 41 (2018) 1559-1575.

[26] G. Qian, J. Zhai, Z. Yu, W. Lei, W. Wu, Non-proportional size scaling of strength of concrete in uniaxial and biaxial loading conditions, Fatigue Fract. Eng. Mater. Struct. 41 (2018) 1733-1745.

[27] Yanzeng Wu, Yaowu Xu, Xiang Guo, Rui Bao, Fatigue life prediction based on equivalent initial flaw size for Al-Li alloy 2297 under spectrum loading, Int. J. Fatigue 103 (2017) 39-47. 


\section{Nomenclature}

a: crack size

$E_{i}$ : crack initiation energy

$E_{t}$ : impact energy

$E_{p}$ : crack growth energy

E: Young's modulus

$\nu$ : Poisson's ratio

$\gamma_{p}$ : surface energy to create a surface crack

$E_{e}$ : elastic deformation energy

$E_{d}$ : plastic deformation energy

$\Delta T_{41 \mathrm{~J}}$ : shift temperature at the energy of $41 \mathrm{~J}$

$\triangle$ USE: shift temperature at upper shelf energy

$Q$ : stress strengthening coefficient,

$\sigma_{s}:$ yield stress

$\sigma_{f}:$ facture stress

$\sigma_{c}:$ critical stress

$D B T T$ : ductile-to-brittle transition temperature

$R P V$ : reactor pressure vessel

USE: upper shelf energy 